\title{
Healthcare in overview of Turkey
}

\author{
Munis Dundar • Aslı Subasioglu Uzak • \\ Yesim Karabulut
}

Received: 26 August 2010 / Accepted: 17 September 2010/Published online: 8 October 2010

(C) European Association for Predictive, Preventive and Personalised Medicine 2010

\begin{abstract}
Turkey is one of the leading countries with its developing economy, high young population, and with its geopolitical location being an intersection between Asia and Europe. It is aimed at setting a good example for developed and developing countries with its health policy targets. We reported and discussed here the demographic data of Turkish population, the main aims of Ministry of Health, social security system and its scope and structure, health services, healthcare institutions and their infrastructures, human resources in health, health staff training and also outline of Turkish foreign policy. We mentioned predictive, preventive, personalized and participatory medicine according to Turkey's healthcare approach.
\end{abstract}

Keywords Healthcare services (systems) - Targeted preventive measures · Population screening · Public health insurance $\cdot$ Personalized medicine $\cdot$ Medical education

\section{Introduction}

Turkey is the intersection point of Asia, Europe and Africa continents and it is so-called "Lands of the old World" since it is one of the most strategic countries in the world with its geopolitical position and its unique bridge between eastern and western civilizations and also between all religions.

Turkey is encircled from three sides by seas; the Aegean Sea from West, the Black Sea from North and the Mediterranean Sea from South, which are connecting Turkey to the World's oceans. With this special position

M. Dundar $(\bowtie) \cdot$ A. S. Uzak $\cdot$ Y. Karabulut

Medical Faculty, Erciyes University,

Kayseri, Turkey

e-mail: dundar@erciyes.edu.tr
Turkey is like a neighbour with the entire world, and it has been the center of the major trades and migration routes throughout the history. Turkey is bordered by eight countries: Bulgaria from Northwest, Greece from West, Georgia from Northeast, Armenia, Nakhchivan and Iran from East and Iraq and Syria from Southeast.

Turkey is the founding father of some organizations, all of which are crucial in the world, which are Organization for Economic Co-operation and Development (OECD, 1961), Organization for Security and Co-operation in Europe (OSCE, 1973), Economic Cooperation Organization (ECO, 1985), United Nations (UN, 1945), Organization of the Islamic Conference (OIC, 1969), Black Sea Naval Co-operation Task Group (BLACKSEAFOR, 2001), Developing-8 (D-8, 1997) and it is also a member of the World Trade Organization (WTO, 1995), European Court of Human Rights (ECHR), North Atlantic Treaty Organization (NATO, 1952), Council of European (COE, 1949). Besides all of these, Turkey has also started full membership negotiations with the European Union (EU) officially in 2005 .

Turkish foreign policy is aiming a friendly and harmoniously relationship with mainly with its neighbours and also with all the countries all over the world to provide international cooperation and international peace, and also peaceful solutions to the conflicts, and to contribute regional peace, stability and prosperity. Turkey's wide range of regional and international membership is a reflection of its multifaceted foreign policy.

\section{Demographic data of Turkish population}

The population of Turkey stood at 72.561 .312 with a growth rate of $1.15 \%$ based on the 2009 census and its 
populations of $50.3 \%(36.462 .470)$ and $49.7 \%$ (36.098.842) formed by man and woman, respectively. People within the $15-60$ age-group constitute $65 \%$ of the total population, the 0-14 age-group corresponds $26 \%$ of the population. While the proportion of the population residing in urban areas is $75.5 \%$ (54.807.219), $24.5 \%$ (17.754.093) of the population resides in countryside. Urban area having the highest rate of the population is province of Istanbul with $99 \%$, while the lowest is province of Ardahan with 31.9\% [1] (Table 1).

\section{Maternal and infant (child) healthcare services in Turkey}

The annual infant mortality rate was about 52.6 deaths per year per 1,000 live births in 1993; it was reduced to 17 deaths per year per 1,000 live births in 2008. The maternal mortality rate was around 70 deaths per year per 10,000 live births in 1998; it was reduced by 4 times and become around 19 deaths per year per 10,000 live births in 2008 [4] that reduced mortality rates are the results of improving prenatal care and careful follow up of the pregnancies. The competent authority on this issue is Maternal and Child Health and Family Planning General Directorate under the Ministry of Health (Fig. 1).

The main aims of this unit can be listed as follows,

1. By taking mother health, child health and family planning issues into consideration to see problems and current situation and to determine related objectives. In line with the objectives to prepare plans and programs, implement, monitor and evaluate them. To coordinate all kinds of related services with mother health, child health and family planning within the country.

2. In order to have a number of children bearing families can care whenever they want to provide constant and effective family planning service, to monitor and evaluate them.

3. Taking the necessary measures to ensure having a child to married people diagnosed with infertility.

Table 1 Demographic data, taken with permission from [2]

\begin{tabular}{|c|c|c|c|}
\hline Years & 2000 & 2007 & 2008 \\
\hline Population (1000) & 67,804 & 70,586 & 71,517 \\
\hline Rural population (\%) & 35.1 & 29.5 & 25.0 \\
\hline Urban population (\%) & 64.9 & 70.5 & 75.0 \\
\hline $\begin{array}{l}\text { Annual population growth } \\
\text { rate }(\%)\end{array}$ & 1.38 & 1.18 & 1.15 \\
\hline Crude death rate $(\%)$ & 0.66 & 0.64 & 0.64 \\
\hline Crude birth rate (\%) & 2.03 & 1.81 & 1.79 \\
\hline
\end{tabular}

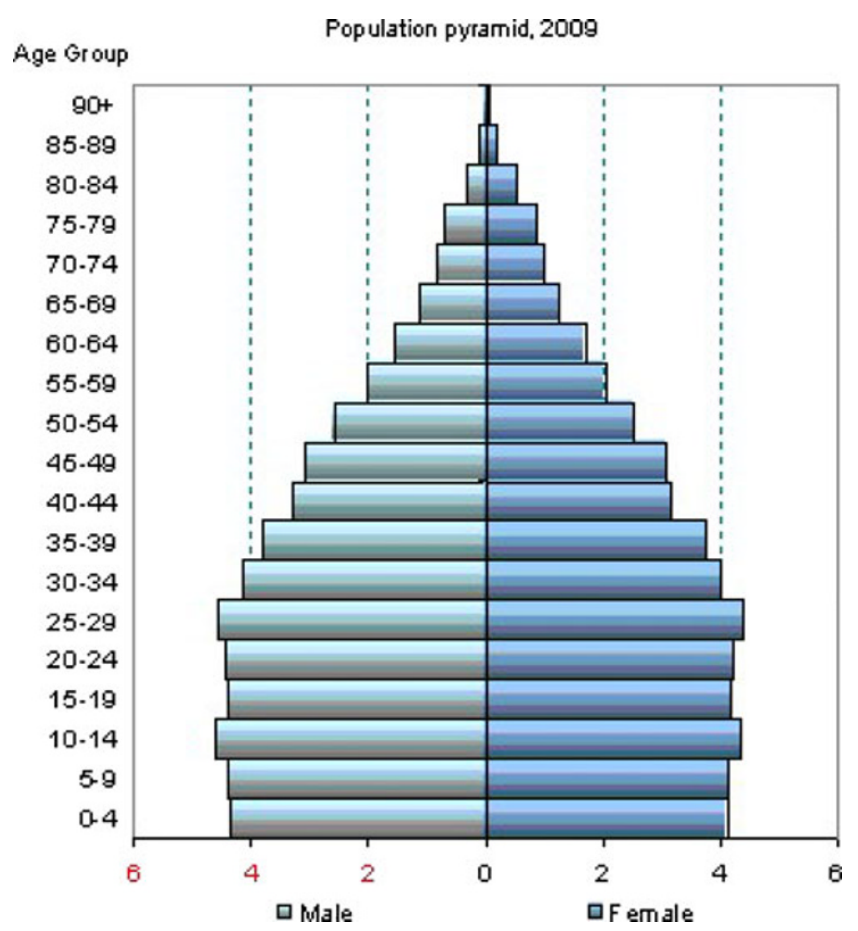

Fig. 1 Population pyramid, 2009, taken with permission from [3]

4. Identification of the necessary measures, implement, monitor and evaluate them for caring and controlling of the prenatal, infant, play age, school age, adolescence periods so as to preserve physical and mental health of children.

5. For preventing families from having children with physical and mental disabilities planning medical and genetic counseling services in cooperation with relevant organizations and agencies to implement.

6. To maintain physical and mental health of mother and baby taking the necessary measures to carry out controls before pregnancy, during pregnancy and postnatal period.

7. To protect health of child and mother at birth ensuring health conditions plans and programs and implement, monitor, and evaluate them.

8. To provide training and consultancy services to prepare plans and programs for the couple will marry or being married according to the woman's health, family planning and marriage, medical and social issues implement, monitor and evaluate them.

9. In cooperation with relevant units of the Ministry of Health providing child health and family planning training to health personnel.

10. Making cooperation with national and international institutions and organizations regarding mother and child health and family planning issues [5]. 
Moreover, to protect and improve mother and child health prepared and implemented some of the projects by the unit are

- Prenatal and Neonatal Mortality Prevention Program

- Iodine Deficiency Disorders and Salt Iodization Program

- Prevention of vitamin D insufficiency in infants and Bone Health Protection Project

- Hemoglobinopathy Control Program

- Mother and Child Death Prevention Project

- Making "strategies developing projects" to meet the needs of health information and services of adolescent reproduction.

Development of health information, identifying the factors that affect health and taking measures for dealing with them quickly, "Public Health Action Programme" memorandum of understanding signed with EU.

\section{Real gross domestic product per person according to purchasing power parity}

Turkish economy's annual average gross domestic product (GDP) growth rate was 5.3\% from 1980 to 1990 and 4.5\% from 1990 to 1998, which were higher than the world average. Turkish economy shrank by $3.1 \%$ from 1999 to 2001 as a result of the economic crisis. The GDP growth rate since 2002 average is $7.8 \%$, which made Turkey one of the most fast growing economies in the world. Growing young population of Turkey has continued to its growth with each passing day [6].

\section{Social security system and its structure}

"Everybody has the right to have social security" according to 60th item of Turkish Constitution that includes provision of "State takes necessary measures to ensure security and sets up organizations". Based on this provision, social security institution; that brings social insurance institutions, insurances self-employed institutions, the general directorate of retirement fund together under the same roof in order to transform five different retirement systems including public officers, service contract wage employees, agriculture wage employees, self employees, agriculture self employees, into one retirement system which gives equal rights and responsibilities, which was established in accordance with 20.05.2006 dated social security institution act and it keeps its works by the contributions of all its staff and by displaying individual and public energy in order to give more qualified service to our citizens. Furthermore there are private funds in order to help staffs of banks, insurance and reinsurance companies, chambers of commerce and industry and also to their unions (Fig. 2). Protective and preventive social services giving to care or/ and protection needed people or people proved their neediness at Community Center, Family Counseling Center, Children and Youth Centers.

\section{Impact of health services}

Since the establishment of the Republic of Turkey recorded improvements particularly in health sector has reached to some levels that cannot be underestimated. More efficient use of resources for the planned development period began in 1960s, an important success achieved in the fight against infectious diseases and to meet the needs of health institutions and health personnel important steps taken. Although behind the average in developed countries when health indicators were considered, significant steps have been taken to close the gap. Life expectancy stood at
Fig. 2 Scope of social security in Turkey, taken with permission from [7]

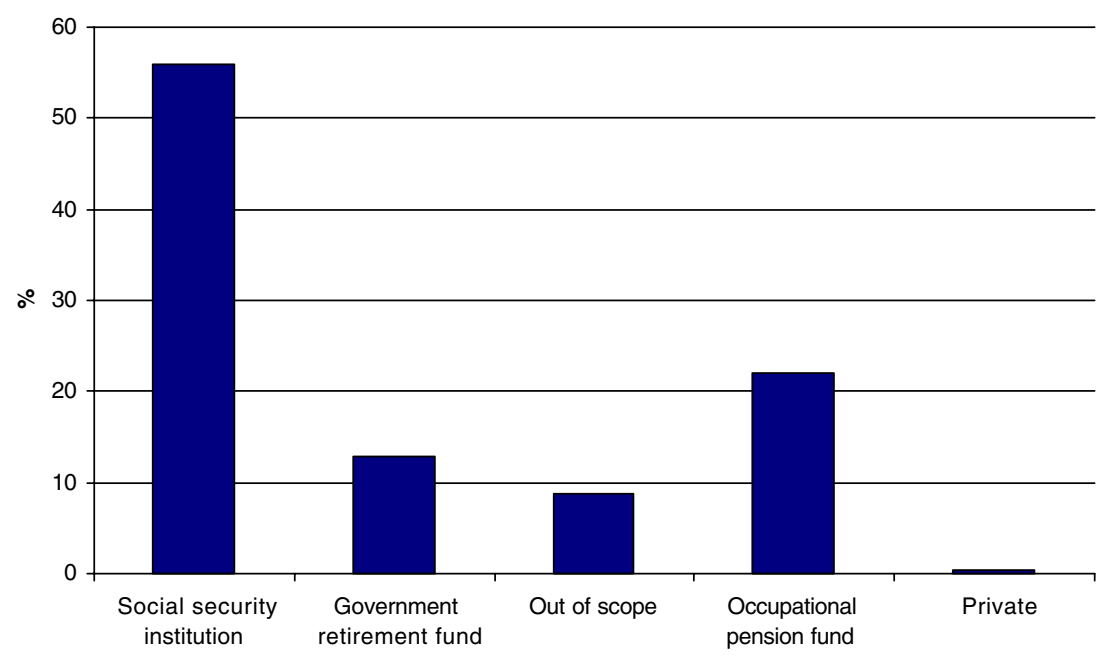


68.9 years for men and 73.8 years for women in 2005. It is estimated that life expectancy will reach 73.2-year and 76.4-year for both sexes between 2015-2020 and 20352040 , respectively [8].

Strengthening prevention and preventive health services and in the context of giving special attention to mother and child health, Hemoglobinopathy Control Program, National Newborn Screening Program, Measles Elimination Program and Breastfeeding Protection, Promotion, Support and Prevention and Control of the Iron Deficiency Anemia Projects were introduced. In addition to these, the National Reproductive Health Strategic Plan and Action Plan have been completed. Average of vaccinated children was $88 \%$ in 2000 and as a result of efforts to increase proportion of vaccinated children throughout the country was elevated $96 \%$ of average in 2008. Rubella, mumps, meningitis and hepatitis $\mathrm{B}$ vaccines were included in the free of charge vaccines [9]. When hospital mortality statistics questioned according to the ICD-10 main diagnostic groups and gender in 2008 (Distribution of Hospital Deaths by ICD-10 Main Diagnosis Codes and Gender, (\%), Turkey 2008), in the first three places I00-199 Circulatory system diseases with $34.3 \%$, C00-D49 Neoplasia with 15.3\%, and J00-J99 Respiratory diseases with $11.4 \%$ took part [10]. According to the statistics of some infectious diseases for the years examined, the incidence of measles was 23.6 per year per 100,000 populations in 2000 , and due to the intensive vaccination program decreased to 0.006 . Likewise, the incidence of malaria has dropped to 0.3 from 16.9 [11].

The most common cancer in women ranking in the first series, despite screening program and mammography, is breast cancer with $41 \%$ of the female population. Colorectal and thyroid cancers with $14.3 \%$ and $12.2 \%$ follow it, respectively. The most common cancer in men ranking firstly is lung and bronchial cancer $(70 \%)$, secondly is prostate cancer $(29 \%)$ and thirdly is bladder cancer $(21 \%)$. There is a unit for producing projects to deal with these issues and diagnosis of cancer in the early stage under the Ministry of Health called "Cancer Control Department". The tasks of the units are;

a. Planning of cancer fighting services, and to implement and organize these services according to the determined policies and objectives;

b. Gathering cancer related all kinds of statistical data, making research and investigation and then encouraging people about these, to evaluate necessary preventive and curative services in cancer fighting according to obtained information by observation and investigation, to identify necessary measures, to implement and enforce them;

c. Build health facilities of cancer fighting or to cause people to establish them; d. To allow opening of the public institutions and the real and legal entities and volunteer organizations or any medical facilities providing determined standards and serving or working in cancer fighting, controlling and steering them;

e. To ensure voluntary participation of the people to fight cancer and support them, to cooperate with voluntary organizations, and to provide assistance and guidance to the organizations within the bounds of possibility;

f. Training of personnel will take part in cancer fighting and to identify the necessary measures to implement and enforce these measures;

g. Taking necessary steps for conduction of public education services in cancer fighting by making collaboration with other agencies and organizations [12].

One of the important basic preventive health services working under the Ministry of Health is associated with tuberculosis (TB). One of the primary healthcare units and the competent authority dealing with this issue under the Ministry of Health is Head of Department of Tuberculosis Control. Practices of the tuberculosis control and the status of tuberculosis in countries are followed with the standard recording and reporting system and by World Health Organization and World Health Organization of European Region including Turkey. Gathering data on tuberculosis is published with the "Global Report" and "European TB Surveillance Report" per year. This report reveals the status of "Directly Observed Treatment Strategy", infrastructures reflecting the political commitment of the Ministry of Health, budget, human resources and practices in the our country. "Tuberculosis in Turkey, the 2009 Report" prepared by Individual data lays out in details that more successful tuberculosis-fight were carried out in 2009 compare to 2007 and 2008 Reports. The goals of reaching case detection rate for new smear-positive patients to $70 \%$ and treatment success rate to $85 \%$ has been accomplished in the worldwide Western Pacific Region and in 36 countries, 2007. Turkey has achieved its goals of this year of the World Health Assembly both in finding treatments and cases. Thus, Turkey became one of the 36 countries that reached the targeted areas. In Turkey, there are totally 243 Tuberculosis Control Dispensary serve on this purpose. Determining Acid-resistant Bacilli (ARB) by microscopy is possible almost all provinces in Turkey. There are 19 cities that can make bacteria culture. National TB Reference Laboratory continues to work under the Head of the Refik Saydam Hifzıssihha Centre in Ankara. To carry out these services 2,611 health personnel have been serving since the end of 2008. The budget of the Ministry of Health under the Health Transformation Program has shown a significant increase between 2005 and 2009. The Health Budget has 
increased two-fold from 2007 to 2009. The share of tuberculosis-fighting services increased as related with the increase rate [13].

\section{National healthcare institutions and their infrastructures}

The impact of the public sector continues in terms of health service delivery. $92 \%$ of hospital beds and almost all of the preventive health services belong to public sectors. To encourage private sectors to make investment in health is ongoing. Number of hospitals in the country with total bed capacity of 190,000 patients has reached 1,350 in 2008 with contribution of the private sectors (Fig. 3). According to the data of Curative Services General Directorate of the Ministry of Health in 2008 number of the beds serving the intensive care units (Intensive Care Beds by Number of Sectors, 2008) is 14,000 and approximately 4,000 out of them are for neonates. Bed capacity usage rate had reached to $64.9 \%$ (Fig. 4). There are totally of 6,305 different places given basic health services except hospitals. Out of them, 4,540 are Village Clinic, and 1,765 are Family Health Centre. There are 373 Public Health Centers, 225 Primary Child Health Care and Family Planning Centre (MCHFP Center), 243 Tuberculosis Control Dispensary, 84 Cancer, Early Diagnosis, Screening and Education Center, which provide primary healthcare services. There are 112 Emergency Stations in 1,308 different points across the country. In addition to these, while number of dialysis centers providing services for patients with Chronic Renal Failure was 443 in 2002, it increased two-fold and reached 830 across the country in 2008. There are 13,005 serving devices and a large number of them using in these centers belongs to private sectors (2008) [14].

\section{Public health insurance and foreseen optimizations}

Uncovered citizens by health insurance can still benefit from free medical treatment as it was initiated in 1992 with the "Green Card" application framework and almost 13 million citizens; approximately $19 \%$ of the total population takes advantages of this Green Card. Expenses of outpatient treatment and drug have been paid from the Ministry of Health budget for the Green Card holder since the 1st of January 2005. Moreover, civil servants, the insured employees and pensioners, farm workers and retirees with their family members' hospital and outpatient costs are covered by the state regardless of the kind of the hospital; private or public health hospitals etc.

Ongoing Health Transformation Program provides; planner and controller of the Ministry of Health structure; collects everyone under one of the public health insurance; a common, easily accessible and friendly healthcare system; strengthened primary healthcare and family medicine; effective gradually transfer chain, health enterprises possess administrative and financial independency; health manpower, equipped with high motivation, knowledge and skills; science committees to support system and education; the quality and accreditation for qualified and effective health services; corporate restructuring in rational medicine and materials management; medical devices institutions; decision processes for effective health information system accesses to information.

The development of European Union health information, identifying the factors that affect health and to take quick action against them "Public Health Action Program" memoranda of understanding was signed.

Solution being prepared for the country's current dental health problems is "Continuing Oral Health Education Program". Through this education program our aim is to be
Fig. 3 Distribution of hospitals in Turkey
Distrubution of hospitals in Turkey

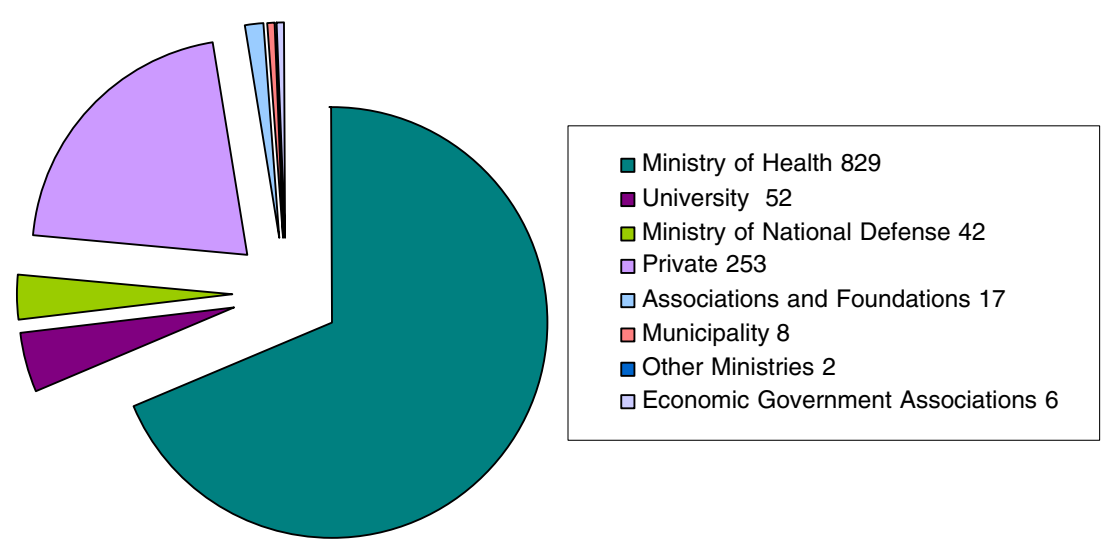


Fig. 4 Distribution of numbers of beds according to the organizations in Turkey
Distribution of numbers of beds according to the organizations in Turkey

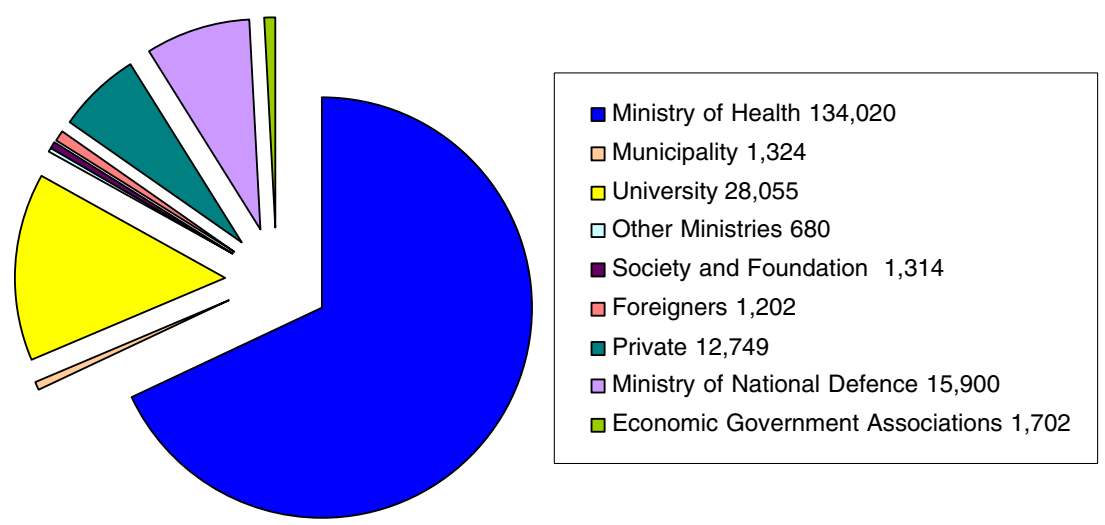

able to increase oral and dental health information, enhancement of gaining the right habits, and increase the percentage of tooth-brushing children between 6 and 12 ages to $90-100 \%$ by helping to develop oral and dental health education programs of country-wide all primary schools 1-2-3-4 and 5th grade students in order to create a healthy generation. There are 622 dental clinics with 4,294 dental units servicing to inhabitants in 2008.

\section{Human resources in health}

The number of doctors serve for the health across the country are 113,151 according data of 2008. Out of them, 57,000 are specialists, 35,000 are general practitioners and 20,000 are physician assistants. There are 100,000 nurses, 78,000 health officer, 48,000 midwives, 20,000 dentists, 25,000 pharmacists in the country. The number of doctors per 1,000 people although there are some changes in the west and east of the country, it is around 1.5 [15].

\section{Health staff training in Turkey}

Health education in Turkey given in Medical Vocational High Schools in the level of secondary education, and it is given in Faculty of Medicine, training doctors, and Medical Vocational High Schools in the level of universities as well.

Medical Vocational High Schools are the schools that are established in order to train intermediate staff for public and private bed and non-bed health institutions and organizations depend on connected to the ministry of health. General culture, health, basic science, vocational competence, Foreign Language Programs are applied. In Anatolian Programs, English is the main course. In Medical vocational high schools; trainings in the fields of emergency health services, emergency medical technician, anesthesiology and reanimation, anesthesia technician, environmental health, environmental health technician, dental prosthesis, dental prosthesis technician, orthopedic prosthesis, or thesis, orthopedic prosthesis, or thesis technician, radiology technician, medical laboratory, medical laboratory technician, health services secretary ship, medical secretary ship, are given in 9th and 10th grades, Health, in nursing department 9th, 10th and 11th grades; Health, emergency medicine, anesthesia, environmental health, dental prosthesis, radiology, medical laboratory, medical secretary ship, in 11th and 12th grades 4 year education is given at secondary education level. 50,306 students have been educated in 102 Medical Vocational High Schools of Turkey by 2008-2009 academic years, and 10,000 of them have been graduated from various departments. There are same or similar departments in Universities and Faculties with the ones that are in Medical Vocational High Schools [16].

There are ten private and 54 state universities. So, totally 64 medical schools according to the Board of Higher Education and 34,869 students continue their medical schools educations in Turkey are exist. According to a data from the last 3 years, there were 4,651, 4,764 and 4,465 students who were studying in the 2008-2009, 2007-2008, and 2006-2007 academic year of medical school, respectively. Doctoral education takes normally 6 years, but in some universities medical schools start with a year of preparatory courses in English in addition to 1 year. Specialization education in medicine can be achieved with a central exam, and it takes 4 and 5 years depending on medical and surgical branches, respectively.

Apart from all these basic training of health personnel working in state-owned companies, doctors, nurses, technicians and other personnel in various periods of time with the designation of the Ministry of Health, they take inservice training to see current innovations. 


\section{Outline of Turkish foreign policy}

The basis of the Turkish foreign policy and resources is Ataturk's saying "Peace at Home, Peace in the World". As withstanding this saying, it is aiming a friendly and harmoniously relationship with mainly with its neighbours and also with all the countries all over the world to provide international cooperation and international peace, and also peaceful solutions to the conflicts, and to contribute to the regional peace, stability and prosperity.

Turkey became a member of the League of Nations in 1932 and it was among the founding members of the United Nations (UN) in 1949 after the Second World War, and then adopted the Universal Declaration Human Rights. Same year, as being founding father of the European Council was followed. Turkey's wide range of regional and international membership is a reflection of its multifaceted foreign policy. UN, NATO and the EU led peacekeeping operations, noteworthy contribution and human caused or natural disaster affected countries made substantial humanitarian and development assistance put Turkey into a "donor" country position in many places of world.

Turkey contributes regional and global peace, stability and proved its ability for those. Turkey has put its nomination for temporary membership to UN Security Council on the UN's 36th General Assembly elections will be held during the period 2009-2010.

\section{Conclusion}

Predictive and preventive health services are one of the main aims of health policy in Turkey, which is one of the developed countries. The big budget dedicated to the issue is extremely important. This case is also emphasized in Ninth Development Plan of Turkey that covers 20072013 years. Predictive, Preventive and Personalized Medicine (PPPM) is also is the fundamental principle of family practice. In this scope these are the essentials aim of basic health services to reach more individual with lower cost, to pre-determine the illness through screening programs, prevent the illnesses with vaccine programs.

In the scope of Ninth Development Plan there are improvements in reducing infant mortality rate, bed and physician numbers that are the important signs of healthcare access and their ratio to population. Infrastructure and health personnel needs are covered and their distribution is balanced across the country in order to improve the health services. General health insurance system that facilitates the access has been implemented. Quotas of education programs have been increased, quality of medical education have been achieved to a structure appropriate for country needs and international standards by developing skills basic health services of students in order to meet health personnel shortage. Furthermore in-service training has been increased in order to improve the quality of healthcare workers.

A patient oriented health system has been created and legal regulations have been set up to prevent malpractice in medicine. In addition, the awareness of citizens and health personnel about patient rights has been increased, units dealing with patient rights have been established in health institutions and this practice has been spread. It is planned to provide a better quality of service by compulsory health insurance system for employees going in to effect and so physicians is also planned. Quality of health services, particularly in primary level health services, has been improved by enhancing the qualifications of the personnel and the infrastructure. The family medicine service model has been spread to all provinces since 2008. In order to make the operation of hospitals more efficient and improve the quality of their services, hospitals have been gradually made autonomous in financial and administrative terms.

Following the principle of prevention before treatment, preventive healthcare services, targeted in preventable diseases, primarily communicable diseases and diseases related to maternal and infant health, as well as in the areas of food, consumer and environmental health have had priority in the allocation of resources. With the efficient operation of the referral system and widespread use of information systems, provision of services at hospitals has been facilitated and monitoring of health expenditures has been ensured. Health personnel and the people have been made more conscious about the rational use of medicine. The number and qualifications of personal working in preventive healthcare services has been increased. With birth control educations; in order to prevent the unwanted pregnancies, educations; in order to prevent smoking, programs that deal with well balanced diet, routine cancer screening and information programs, community was made conscious of healthy life styles. The planning, regulatory and supervisory role of the Ministry of Health has been strengthened [17].

As a result of all of these, Turkey will be one of the leading countries in the last decade with its developing economy, high young population, and with its geopolitical location being an intersection between Asia and Europe, it is aimed to set a good example for developed and developing countries with its predictive, preventive and personalized medicine and health policy targets. In the scope of the health policy of Turkey it is aimed to give equal health service to everyone and be sure that everyone gets the benefits of the health service with General Health Insurance.

Medicine will begin to get more predictive and personalized over the next years. So Turkey Health Policy must 
give priority to this subject. Relevant subunits have to be established under the head of Ministry of Health. Courses about this case have to take place in the syllabus of medical faculties. Awareness of public should be raised about basic principles of predictive and personalized medicine and the public should be provided to participate in this case and patients should be encouraged to take control of their healthcare. Patients should be enabling to reach these units by increasing the number of developed technologic centers. This new approach will have a significant effect on various industries, including pharmaceuticals, food and insurance, as well as healthcare. Thus necessary studies should be fulfilled in order to meet the deficits of substructure and staff.

Children are controlled by their family physicians, who are attained after they born, and their developments are experienced and they get free shots with this system. Although there is a development system like this for children, there is not generally any system for adults. All individuals should undergo medical examination regularly without considering age.

This predictive and preventive health system may cause a remarkable save in the budget that is used for health expenses. It is essential that Health Ministry should attain interested unions to develop personal health system and be sure to make it possible that union's health service is personal. Intelligent political regulations in the healthcare sector must be arranged carefully and participation of private sector should be provided.

Consequently the aims are organized population healthcare screening of all ages, targeted prevention of the most frequent diseases and pathologies, increasing the usage of non-invasive diagnostic techniques, personalized patient treatment with new technologies. All these improvements provide public to improve the quality of life first of all and also economical advantages.

\section{References}

1. Address Based Population Registration System Population Census 2009: Population by age group and sex ratio, 2009. Ankara; 2010. p. $1-5$.

2. Turkey Statistical Institute official web site. http://www.turkstat. gov.tr/PreTablo.do?tb_id=39\&ust_id=11. Accessed July 2010.

3. Turkey Statistical Institute official web site. http://www.turkstat. gov.tr/PreHaberBultenleri.do?id=6178. Accessed July 2010.

4. TUIK-Death Statistics Turkey 2008. Ankara; Dec 2009. p. 2-13.

5. ACSAB. http://www.saglik.gov.tr/ACSAB. Accessed July 2010.

6. Turkey Statistical Institute official web site. www.tuik.gov.tr.

7. Prime Ministry General Directorate of Press and Information, Turkey promotion Web site. www.turkiyemiz.gen.tr. Accessed July 2010.

8. The Ministry of Health of Turkey. Health Statistic Yearbook 2008. Life expectancy at birth by years, Turkey. Ankara; 2010. p. 11-12.

9. The Ministry of Health of Turkey. Health Statistic Yearbook 2008. Life expectancy at birth by years, Turkey. Ankara; 2010. p. 31.

10. The Ministry of Health of Turkey. Health Statistic Yearbook 2008 distribution of hospital deaths' reasons by ICD-10 diagnosis codes, top three, total, (\%), 2008; p. 127.

11. The Ministry of Health of Turkey. Health Statistic Yearbook 2008. Incidence of some selected infectious diseases by years, (per 100.000 population), Turkey. p. 22-23.

12. http://www.kanser.gov.tr. Accessed July 2010.

13. Türkiye'de verem savası 2009 raporu. www.saglik.gov.tr/VSDB. Accessed July 2010.

14. The Ministry of Health of Turkey. Health Statistic Yearbook 2008. Health care facilities and infrastructures. p. 43-61.

15. TUIK. Bölgesel göstergeler TR 2009. Nüfus ve sosyal yapı. Ankara 2010. p. 54.

16. http://sdb.meb.gov.tr/istatistik.html. Accessed July 2010.

17. Official Gazette, 01.07.2006 date and number 26.215, Grand National Assembly of Turkey Decision, Ninth Development Plan (2007-2013). 